www.jmscr.igmpublication.org

Index Copernicus Value: 79.54

ISSN (e)-2347-176x ISSN (p) 2455-0450

crossref DOI: https://dx.doi.org/10.18535/jmscr/v7i3.220

\title{
Lipid Pattern of Chronic Kidney Disease Patients on Hemodialysis and on Conservative Management- A Comparative Study
}

\author{
Authors \\ Dr Raghu Rama Reddy .A ${ }^{1}$, Dr Girija. $\mathbf{S}^{2^{*}}$, Dr Ravi Kumar . $\mathbf{P}^{3}$ \\ ${ }^{1}$ Junior Resident, Department of General Medicine, SMVMCH, Kalitheerthalakuppam, Puducherry 605107, India, \\ Email: aaluriraghu@gmail.com \\ ${ }^{2}$ Associate Professor, Department of General Medicine, SMVMCH, Kalitheerthalakuppam, Puducherry 605107, India \\ ${ }^{3}$ Consultant Nephrologist, SMVMCH, Kalitheerthalkuppam, Puducherry 605107, India \\ Email: ravi.pkr@gmail.com \\ *Corresponding Author \\ Dr Girija .S \\ Email:girijagops@gmail.com
}

\begin{abstract}
Introduction: Chronic renal failure (CRF) is an irreversible condition, which is indicated by significant reduction in glomerular filtration rate, or irreversible destruction of kidney tissue.1 CRF is characterized by a wide variety of biochemical disturbances and numerous clinical symptoms and signs. Plasma cholesterol levels are usually normal in ureamia but elevated after renal transplantation. In renal failure, these abnormalities of carbohydrate and lipid metabolism presumably contribute to increased risk of atherogenesis, which may be troublesome in patients receiving long-term dialysis.8,9.

Thus the present study was conducted to compare the lipid profile in chronic kidney disease patients on regular hemodialysis and on conservative management

Materials and Methodology: A Hospital based case control study was conducted in Sri Manakula Vinayagar Medical College and Hospital, kalitheerthalkuppam for a period of 6 months, from May/2017 to October/2017. Patients who were diagnosed with Chronic Kidney Disease and admitted into the medical wards were included in the study. Patients with already known diabetes mellitus, ischemic heart disease, patients who had undergone coronary artery bypass graft, on lipid lowering drugs and history of alcohol consumption and smoking were excluded, from the study. Fasting lipid profiles of patients of chronic kidney disease on conservative management (group-I) and on hemodialysis (group-II) were compared.

Results: A total of 80 patients participated in the study. The mean age of the CRF patients was 53.25 11.04 years. The mean age in our study among the group I participants (40) was $54.41 \pm 10.86$ years and in group II (40) it was found to be $51.87 \pm 11.23$ years. This study showed that total cholesterol, triglycerides, HDL, LDL, VLDL were significantly lower in the CRF patients on regular hemodialysis ( $p<0.05)$. Total cholesterol, triglycerides and VLDL were significantly higher among female gender with $p$ value $<0.05$

Conclusion: Chronic kidney disease, due to its alteration in carbohydrate and lipid metabolism can lead on to increased atherogenesis and contribute to mortality. This necessitates the periodic monitoring and maintenance of lipid profiles within recommended range in CKD patients not on hemodialysis also.
\end{abstract}

\section{Introduction}

Chronic renal failure $(\mathrm{CRF})$ is an irreversible condition, which is indicated by significant reduction in glomerular filtration rate, or irreversible destruction of kidney tissue. In renal failure, dyslipidemia contribute to increased risk 
of atherogenesis, which may be detrimental in patients receiving long-term dialysis.CRF is characterized by a wide variety of biochemical disturbances and numerous clinical symptoms and signs. ${ }^{2}$ The biochemical alteration, ureamia causes haematologic abnormalities, cardiovascular problems, gastrointestinal disturbances, neurologic disorder, osteodystrophy, skin disorder and altered sexual function. ${ }^{3}$ Lipoprotein metabolism also seems to be altered in most patients with renal insufficiency. Dyslipidaemia develops early in renal failure and the disparity between lipoprotein synthesis and degradation in prolonged renal disease results in a pronounced dyslipidemia. ${ }^{4}$

In CRF patients uremia usually develops only after the creatinine clearance falls to less than 10 $\mathrm{mL} / \mathrm{min}$. Uremic patients have elevated serum levels of triglycerides and lipoprotein and this elevated level of this lipid may contribute to increased cardiovascular risk. $^{6}$ Cardiovascular related mortality in CKD patients is observed to be 30 times higher than the general population. Atherosclerosis is recognized as the major cause of cardiovascular disease in hemodialysis and it is responsible for $40 \%$ to $50 \%$ deaths in this population. The accelerated atherosclerosis is due to hyperlipidemia , uremic toxins, inflammation , oxidative stress and endothelial dysfunction ${ }^{13,14}$. However a study by Jay et al ${ }^{7}$ (1998) showed that plasma cholesterol levels were usually normal in ureamia but elevated after renal transplantation. ${ }^{5}$ The present study was conducted to compare the lipid pattern in chronic kidney disease patients on regular hemodialysis and on conservative management.

\section{Materials and Methods}

Ahospital based case control study was conducted in Sri Manakula Vinayagar Medical College and Hospital, kalitheerthalkuppam. The study was commenced after getting approval from the institutional ethical committee over the study period of 6 months that is from May/2017 to October/2017 .All the patients who attended the outpatient and also admitted as inpatients in Department of General Medicine with clinical sign and symptoms of uremia, and confirmed to have Chronic kidney disease with biochemical and Imaging studies were selected for the study. A total of 80 patients who fulfilled the inclusion criteria were included in this study after informed consent. Patients with diabetes mellitus, ischemic heart disease, patients who had undergone coronary artery bypass graft, on lipid lowering drugs and history of alcohol consumption and smoking were excluded from the study. All the patients of chronic kidney disease were subsequently divided into two groups, group I comprised of CRF patients on conservative management (40 patients) and group II comprised of CRF patients on regular hemodialysis (40 patients). Fasting serum lipid levels were analysed which consisted of total cholesterol, triglycerides, low density lipoprotein (LDL), very low density lipoprotein (VLDL), high density lipoprotein (HDL). Data was analysed using the SPSS version 16 software. Descriptive statistics were reported as mean (SD) for continuous variables and frequency (percentage) for categorical variables. Pearson's Chi-square test was used to find association between two categorical variables. A p value $<0.05$ was considered as statistically significant.

\section{Results}

The baseline parameters of the study participants are shown in table -I

Table1: Baseline Characteristics of Study Population

\begin{tabular}{|l|c|c|}
\hline & Group I & Group II \\
\hline $\begin{array}{l}\text { Age (years )Mean } \\
\pm \text { SD }\end{array}$ & $\mathbf{5 4 . 4 1 \pm 1 0 . 8 6}$ & $51.87 \pm \mathbf{1 1 . 2 3}$ \\
\hline Sex (M/F) & $\mathbf{2 6 / 1 4}$ & $\mathbf{3 5 / 5}$ \\
\hline \multicolumn{2}{|c|}{ Random } \\
$\begin{array}{l}\text { Blood Glucose } \\
(\mathrm{mg} / \mathrm{dl})\end{array}$ & $78.2 \pm 12.17$ & $96.05 \pm 18.65$ \\
\hline Urea(mg/dl) & $85.72 \pm 36.08$ & $84.68 \pm 32.20$ \\
\hline Creatinine (mg/dl) & $6.29 \pm 2.90$ & $6.35 \pm 2.51$ \\
\hline
\end{tabular}


Group I- CRF patients on conservative management

Group II - CRF patients on regular hemodialysis

Table 1 shows the baseline characteristics of study population like age, urea, creatininein both the groups. The mean age, RBS, urea and creatinine in group I was found to be $54.41 \pm$ $10.86,78.2 \pm 12.17,85.72 \pm 36.08$ and $6.29 \pm$
$2.90 \mathrm{mg} / \mathrm{dl}$ respectively. While in group II, The mean age, RBS, urea and creatinine in group I was found to be $51.87 \pm 11.23,96.05 \pm 18.65,84.68 \pm$ 32.20 and $6.35 \pm 2.51 \mathrm{mg} / \mathrm{dl}$ respectively.

Fig 1 shows sex distribution of the study participants in both the groups. Majority of the participants were male in both the groups.

Fig 1: sex distribution of the study participants

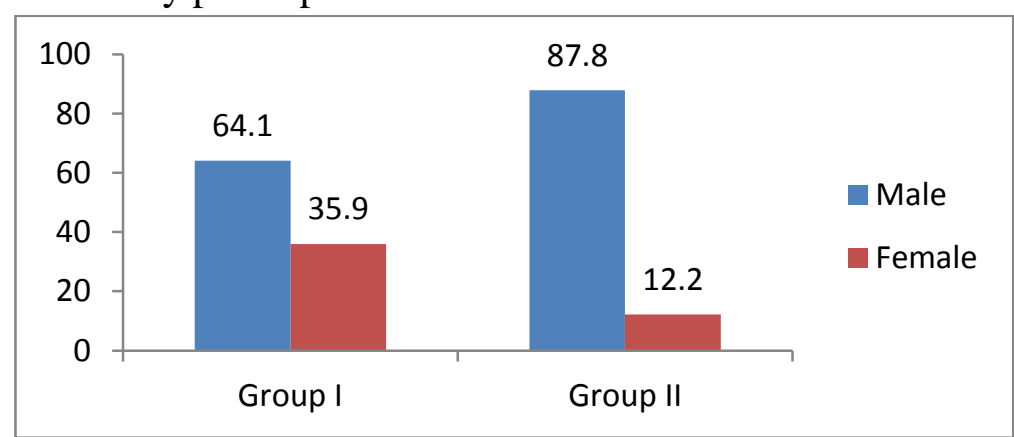

In group-I,64.1\% are male patients and $35.9 \%$ are female. In group-II, $87.8 \%$ are male patients and $12.2 \%$ are female.

Table 2: Lipid Profile among CRF patients on conservative management and patients on regular hemodialysis

\begin{tabular}{|l|c|c|c|}
\hline & Group 1 & Group II & P value \\
\hline Total cholesterol(mg/dl) & $184.85 \pm 46.50$ & $150.70 \pm 25.97$ & $<0.001^{*}$ \\
\hline Triglycerides(mg/dl) & $137.56 \pm 77.05$ & $82.42 \pm 26.57$ & $<0.001^{*}$ \\
\hline HDL(mg/dl) & $38.69 \pm 6.38$ & $34.43 \pm 6.06$ & $<0.001^{*}$ \\
\hline LDL(mg/dl) & $118.72 \pm 38.92$ & $100.42 \pm 21.91$ & $0.01^{*}$ \\
\hline VLDL(mg/dl) & $24.31 \pm 10.06$ & $16.63 \pm 5.13$ & $<0.001^{*}$ \\
\hline
\end{tabular}

*Highly significant $(<0.05)$

Table 2 shows the lipid Profile among Control and regular hemodialysis patients. It was found in this study that total cholesterol, triglycerides, HDL,

LDL, VLDL were significantly lower in the CRF patients on regular hemodialysis . This finding was statistically significant $(\mathrm{p}<0.05)$

Fig 2: Lipid Profile among CRF patients on conservative management and patients on regular hemodialysis

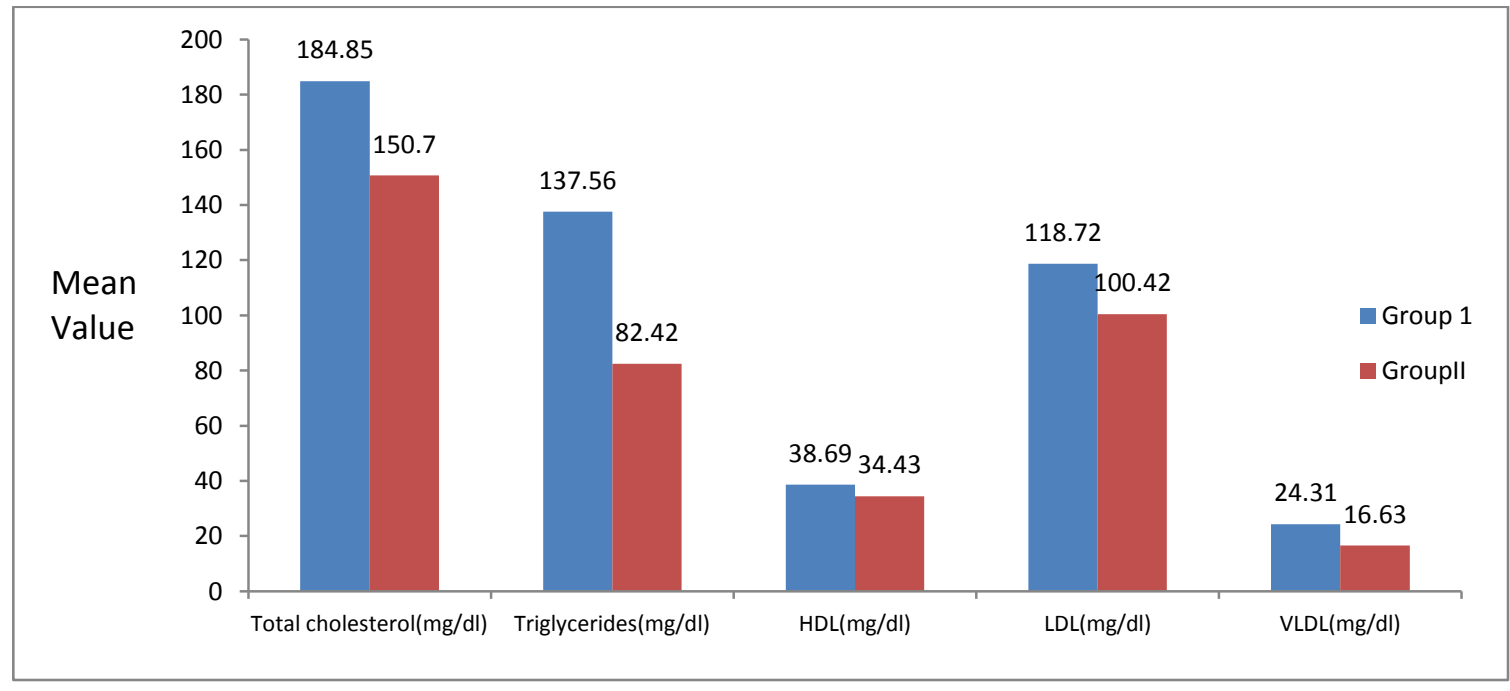


Table 3: Comparison of lipid profile gender wise

\begin{tabular}{|l|c|c|c|}
\hline & Male & Female & P value \\
\hline Total cholesterol $(\mathrm{mg} / \mathrm{dl})$ & $159.03 \pm 36.13$ & $193.94 \pm 46.42$ & $<0.001 *$ \\
\hline Triglycerides $(\mathrm{mg} / \mathrm{dl})$ & $91.46 \pm 38.65$ & $166.56 \pm 91.90$ & $<0.001 *$ \\
\hline HDL $(\mathrm{mg} / \mathrm{dl})$ & $34.98 \pm 4.99$ & $41.50 \pm 8.65$ & $<0.001 *$ \\
\hline LDL $(\mathrm{mg} / \mathrm{dl})$ & $106.46 \pm 32.22$ & $120.94 \pm 30.97$ & 0.095 \\
\hline VLDL $(\mathrm{mg} / \mathrm{dl})$ & $18.54 \pm 7.70$ & $25.83 \pm 9.81$ & $<0.001 *$ \\
\hline
\end{tabular}

Table 3 shows that total cholesterol, triglycerides, HDL and VLDL were significantly higher among female with $\mathrm{p}$ value $<0.05$.

\section{Discussion}

In this hospital based study, the lipid profile of patients with CKD were analysed in two groups, on hemodialysis and on conservative management over a period of 6 months.

The mean age of the CRF patients in the study was 53.25 11.04 years, which was higher as compared to the study done by Adejumo OA etal $^{10}$ and Kumari RA etal ${ }^{11}$, where mean age was found to be $46.98 \pm 16.81$ and 45.28 years respectively. The mean age in our study among the group I participants was 54.41 10.86 years and in group II it was found to be $51.87 \pm 11.23$ years. Majority of the participants in both the group were males. Mean Random Blood Glucose, urea, creatinine in group Iand group II was found to be $51.87 \pm 11.23,96.05 \pm 18.65,84.68 \pm 32.20$ and $6.35 \pm 2.51 \mathrm{mg} / \mathrm{dl}$ respectively.

The present study showed that total cholesterol, triglycerides, HDL,LDL, VLDL were significantly lower in the CRF patients on regular hemodialysis $(p<0.05)$. Low HDL levels in CKD patients is shown to be an independent risk factor for the development and progression of chronic kidney disease ${ }^{15}$.Study conducted by Baria D etal $^{12}$ found that there was no significant difference observed between total cholesterol levels in both the groups, HDL cholesterol levels was reduced in CRF patients with hemodialysis and VLDL cholesterol levels found to be higher in CRF patients with hemodialysis .serum cholesterol is normal or below normal in CKD patients, low serum cholesterol levels are shown to be causing higher mortality rate in CKD patients by selectively increasing the oxidized LDL cholesterol $^{16}$.

Our study also illustrated that total cholesterol, triglycerides and VLDL were significantly higher among female with $\mathrm{p}$ value $<0.05$. Adejumo OA etal $^{10}$ had the same finding where, dyslipidaemia was commoner in female CKD patients, where as in the study done by Baria D etal ${ }^{12}$ no significant difference was observed between lipid profile levels among male and female patients. However the comparision of lipid profile between male and female patients was not possible due to unequal distribution between groups.

Limitations of the study are small number of study participants and there is no conclusive information on the influence of gender on lipid profile of CKD patients on hemodialysis and conservative management.

\section{Conclusion}

Chronic kidney disease, due to its alteration in carbohydrate and lipid metabolism can lead on to increased atherogenesis and contribute to mortality. This study which included patients of CKD on hemodialysis had significant reduction in the Total cholesterol, triglycerides, LDL, VLDL levels, compared to the patients on conservative management. This necessitates the periodic monitoring and maintenance of lipid profiles within recommended range in CKD patients not on hemodialysis. It is essential that the dyslipidemia is identified early thus preventing cardiovascular morbidity and mortality. In spite of various studies on this topic inconsistency remains on the favorable lipoprotein pattern of CKD patients on hemodialysis. It is essential that 
multicenter studies are undertaken, to have a conclusive opinion on lipoprotein pattern in chronic kidney disease patients.

\section{References}

1. Dewardener, H.E. An outline of normal and abnormal function. In: The kidney 4th edition Churchill Livingstone New York.1986; 181-235.

2. Mathenge R.N, Mcligego, S.O., Mutua, A.K. and Otieno, L.S The spectrum of echocardiographic finding in chronic renal failure. East African Medical Journal ,2003; 70(3): 97-103.

3. Moronkola O.A, Ojediran M.M, and Amosu A. Menstrual disorder in chronic renal failure patients attending renal clinics in Ibadan, Nigeria. African Health Sciences, 2006; 6 (3): 155-160.

4. Riepponen P, Maniemit J, and Flanwlya, A.C. Immunoturbidimetric determination of apolipoprotein $\mathrm{A} 1$ and $\mathrm{B}$ in serum. Journal of Clinical Laboratory Investigation, 1987; 47: 739-744.

5. Ekonoyan G. The epidemic of cardiovascular disease in patients with chronic renal disease. American Journal of Kidney Disease, 1998; 32: 3-5.

6. Gomez DI, Giammonioa AM, Touceda LA,. Variation in the lipid profile of patients with chronic renal failure with folic acid. International Journal of Vitamin Nutritional Resources, 2003; 73: 215-220.

7. Jay HS, John E, Peter OK, and Nicholas F.I.. Renal and electrolyte disorder. In: Internal Medicine. 5th edition. Mosby Incorporated New York., 1988;738-990.

8. Ahman, P.O, Samuelson D and Alaupevic, $\mathrm{P}$,. Lipoprotein metabolism and renal failure. American journal of Nephrology, 1998; 4: 547-553.

9. Markell Ms, Arimenti, RA, Donavitin G and Sumrani, W. Hyperlipidaemia and glucose intolerance in post renal transplant patient. Journal of American Society of Nephrology, 2004; 163: 202-223.

10. Adejumo OA, Okaka EI, Ojogwu LI. Lipid profile in pre-dialysis chronic kidney disease patients in southern Nigeria. Ghana medical journal. 2016;50(1):44-9.

11. Kumari KR, Srinivas B. Study of Lipid Profile in Patients with Chronic Kidney Disease on Conservative Management and Hemodialysis.

12. Baria D, Joshi V, Shah T, Gandha K, Modi N. Impact of Hemodialysis on Lipid Profile among Chronic Renal Failure Patients - A Case Control Study. International Journal of Scientific and Research Publications 2013;3(7)

13. Moradi H, Vaziri ND. Molecular mechanisms of disorders of lipid metabolism in chronic kidney disease.

14. Kanbay M, Afsar B, Siriopol D, Unal HU, Karaman M, Saglam M, Gezer M, Taş A, Eyileten T, Guler AK, Aydin İ. Endostatin in chronic kidney disease: Associations with inflammation, vascular abnormalities, cardiovascular events and survival. European journal of internal medicine. 2016 Sep 1;33:81-7.

15. Boden WE. High-density lipoprotein cholesterol as an independent risk factor in cardiovascular disease: assessing the data from Framingham to the Veterans Affairs High-Density Lipoprotein Intervention Trial. The American journal of cardiology. 2000 Dec 21;86(12):19-22.

16. Nitta K. Clinical assessment and management of dyslipidemia in patients with chronic kidney disease. Clinical and experimental nephrology. 2012 Aug 1;16(4):522-9. 